\title{
EXAME FÍSICO E SUA INTEGRALIZAÇÃO AO PROCESSO DE ENFERMAGEM NA PERSPECTIVA DA COMPLEXIDADE
}

Physical examination and its integralization in the nursing process in the light of complexity

Examen físico y su integralización al proceso de enfermería en la perspectiva de la complejidad

\section{RESUMO}

Este estudo expõe o exame físico e o processo de enfermagem sob a perspectiva da Complexidade de Morin. Seus objetivos foram: descrever as características da complexidade na realização do exame físico e discutir a sua interação com o processo de enfermagem. Metodologia descritiva e exploratória; 10 enfermeiros foram entrevistados e acompanhados por observação participante. A análise de dados foi realizada através Discurso do Sujeito Coletivo. Nos resultados foram discutidos os eixos "dialógica e recursividade" e "o holograma e a reintrodução do conhecimento". 0 exame físico como componente do processo de enfermagem implica a complexidade do cuidado e o lidar com ordem e desordem do cotidiano, em uma abordagem dialógica e intervenções técnicas e humanas contextualizadas. Conclui-se que o aprimoramento da avaliação clínica, ampliada na complexidade do exame físico, possibilita a integralização do processo de enfermagem para efetividade do cuidado.

Palavras-chave: Exame físico. Processos de enfermagem. Cuidados de enfermagem. Corpo humano.

\begin{abstract}
This study discusses the physical examination and the Nursing Process from Morin's perspective of Complexity. Its objectives are: to describe the complexity of the physical examination and discuss its interaction with the Nursing Process. Using the descriptive and exploratory method, this research was based on data collection aimed at 10 nurses, who were interviewed and followed by participant observation. The analysis was made through the Collective Subject Discourse. As a result, the "dialogic/ recursive" axes as well as "the hologram and the reintroduction of knowledge" were discussed. Physical examination used as a component of the nursing process involves the complexity of care and the management of order and disorder in everyday life. Under a dialogical approach, contextualized technical human interventions are observed. The improvement of clinical assessment, broadened by the complexity of physical examination, enables the integration of the Nursing Process for the effectiveness of care.
\end{abstract}

Keywords: Physical Examination. Nursing Process. Nursing Care. Human Body.

\section{Resumen}

El estudio expone el examen físico y el Proceso de Enfermería por la perspectiva de la Complejidad de Morin. Sus objetivos son: describir las características de complejidad en el examen físico, y discutir su interacción con el Proceso de Enfermería. Se utilizó el método descriptivo y exploratorio para la recopilación de datos destinada a 10 enfermeros, entrevistados y seguidos por la observación participante. El análisis fue realizado a través del Discurso del Sujeto Colectivo. Los resultados se discutieron por los ejes "dialógica y recursividad" y "holograma y la reintroducción del conocimiento". El examen físico como un componente del proceso de enfermería implica la complejidad de la atención y el mantenimiento del orden y el desorden en la vida cotidiana, bajo un abordaje dialógico e intervenciones técnicas y humanas contextualizadas. Se concluye que la mejora de la evaluación clínica, basada en la Complejidad del examen físico, permite la integración del Proceso de Enfermería para la atención efectiva.

Palabras clave: Examen Físico. Procesos de Enfermería. Atención de Enfermería. Cuerpo Humano.

\footnotetext{
'Mestre em Ciências do Cuidado em Saúde pela Escola de Enfermagem Aurora de Afonso Costa (EEAAC). Universidade Federal Fluminense (UFF); Professor Faculdade Souza Marques. Niterói - RJ - Brasil. E-mail: mcarvalho27@yahoo.com.br; ²Doutor em Enfermagem pela EEAN /UFRJ. Pós-Doutor em Psicologia Clínica pela PUC/SP. Professor Titular do Depto. Enfermagem Médico Cirúrgica (MEM/EEAAC/UFF). Niterói - RJ - Brasil. E-mail: eneaspsi@hotmail.com
} 


\section{INTRODUÇÃO}

0 exame físico realizado pelo enfermeiro em sua prática assistencial tem por finalidade avaliar características inerentes ao corpo humano, que vêm a servir como dados subsidiadores ao cuidado oferecido. 0 ensino da semiologia e semiotécnica da enfermagem, devido à ênfase nas técnicas aferidoras, pode restringir a avaliação de enfermagem ao físico, contribuindo para a repetição de uma história clínica padronizada, independente do cliente examinado. ${ }^{1}$

Conhecida pelo processo de coleta de dados de um cliente, a história clínica não é um rígido protocolo que se tem de cumprir, mas trata-se de um acontecer sucessivo das queixas do cliente e do que o profissional de saúde realmente faz em seu benefício, através do raciocínio clínico, além de servir como subsídio para apresentação de um ambiente acolhedor ao cliente, fortalecendo o relacionamento interpessoal. ${ }^{2}$

0 cuidado de enfermagem requer conhecimento acerca dos fundamentos dos conceitos, ${ }^{3}$ existentes entre as relações de aspectos biológicos, psicológicos e sociais, e as implicações psicoafetivas dos sujeitos envolvidos no cuidado de enfermagem - cliente, profissionais, família, comunidade - que caracterizam e implementam a subjetividade do exame físico, podendo este ser realizado considerando as múltiplas nuances humanas e seu contexto. ${ }^{4}$

Nesse âmbito, a complexidade, adotada por Edgar Morin, surge para trazer uma nova visão a tudo aquilo que antes era estudado em separado, desprovido de um contexto e que desconsiderava a interação do objeto e pesquisador. ${ }^{5}$ Tratase, assim, de um paradigma de conjunção e não de segregação; por conseguinte, o físico, o psíquico, social e o cultural estarão interligados em um modelo em rede que merece ser considerado no exame físico.

A aplicação do exame físico, até mesmo por uma estratégia didática, sempre foi empregada utilizando a fragmentação do corpo.' Entretanto, no que tange o cuidado, é preciso direcionar as técnicas e os achados à assistência de um cliente, cujo corpo ultrapassa as linhas anatômicas, e se engendra em conexões que o Processo de Enfermagem abarca.

0 Processo de Enfermagem compreende a metodologia do trabalho dos enfermeiros e constitui-se de cinco etapas inter-relacionadas (investigação, diagnóstico, planejamento, implementação e avaliação) de forma sistemática e dinâmica para promover o cuidado humanizado, dirigido e orientado a resultados, acrescentando ainda seu baixo custo. ${ }^{6}$ Por ser um processo, requer que seja dinâmico e integrado com o contexto da saúde.

Este processo tem viabilizado o fazer em enfermagem, reafirmando-a como profissão com habilidades e saberes específicos. Além disto, tem mostrado resultados eficientes em instituições de saúde (hospitais, ambulatórios, unidades básicas) no que diz respeito à administração da assistência. ${ }^{7}$
0 exame físico integra a primeira fase, onde as características do cliente pontuadas por ele permeiam todo o desenvolvimento do processo. De tal forma, a atividade intelectual do Processo de Enfermagem requer um julgamento do enfermeiro, que precisa associar constantemente os dados ao ser e o ser aos dados, o que, em uma linguagem de complexidade, significa direcionar as partes ao todo e o todo às partes. $^{5}$

Estimulados pela reflexão teórica associativa entre exame físico, processo de enfermagem e a complexidade, desenvolvem-se os objetivos deste estudo: descrever as características de complexidade envolvidas na realização do exame físico de enfermagem; e discutir a complexidade no exame físico e sua interação com o processo de enfermagem.

\section{REFERENCIAL TEÓRICO}

\section{A Complexidade por Edgar Morin}

A complexidade propõe uma nova abordagem para a ciência, em que todas as vertentes científicas possam realizar uma síntese transdisciplinar do conhecimento, apresentandose como alternativa ao paradigma mecanicista e newtoniano, pois rejeita o reducionismo típico das ciências naturais e propõe uma nova abordagem de todos os campos do saber, levando-se em consideração a complexidade dos fenômenos. ${ }^{8}$

Morin afirma que pelo fato da vida humana ser regida pela complexidade, os seres humanos querem estabelecer uma ordem artificial, que rivalize contra a desordem. A complexidade vem para tratar os fenômenos, fatos e eventos científicos sem rejeitar a amplitude complexa de relações. Uma de suas propostas é o advento de uma transdisciplinaridade entre todas as escolas do saber humano. ${ }^{5}$

0 termo complexidade significa "aquilo que é tecido junto", $8: 13$ pode-se dizer que todas as sociedades são complexas, à sua maneira e ao seu tempo. A complexidade concebe o ser humano como um ser complexo, capaz de se auto-organizar e de estabelecer relações com o outro, em um processo de autoeco-organização a partir de sua dimensão ética, que reflete seus valores, escolhas e percepções do mundo. ${ }^{9}$

\section{Exame Físico e o Processo de Enfermagem}

0 exame físico, como integrante da etapa inicial do processo de enfermagem, dispõe de capacidades importantes à sua execução e do embasamento do pensamento do examinador - que executará as demais fases -, reafirmando, assim, o seu caráter complexo.

A realização do exame físico envolve competências técnicas (relacionadas ao domínio de determinadas especialidades), intelectuais (aplicação de aptidões mentais) e cognitivas (integração de capacidade intelectual e domínio de ações e conhecimentos). ${ }^{10}$ 
0 conceito moderno e forte de competência está intimamente relacionado à ideia de resultado ${ }^{11}$; somente 0 saber operacionalizado (saber fazer, saber aplicar, saber agir, saber resolver) é que traz resultados. No entanto, para a concretização dos resultados esperados, é necessária a contemplação da complexidade envolvida no processo, envolvendo a conjugação entre os saberes, em uma atitude transdisciplinar. Considerando o exame físico, por exemplo, a aplicação de técnicas correlacionadas ao raciocínio envolve diversas competências.

0 desenvolvimento do exame físico no processo, segundo a perspectiva da complexidade, requer competências técnicas e científicas, contudo, integradas com a ética, a estética, a objetividade e a subjetividade. Assim, deseja-se que o profissional seja crítico, sensível e capaz de transformar a realidade, considerando o lidar com a ordem e a desordem das coisas.

Ao exame físico são inerentes competências técnicas como a inspeção, palpação, percussão e ausculta. No entanto, é importante refletir a respeito da empregabilidade destas habilidades, suas finalidades, o desencadeamento dos dados obtidos no decorrer do processo, e, principalmente, o que implicará no cuidado do ser humano assistido. Por conseguinte, o sujeito e suas conexões precisam ser considerados como parte da concepção de um cuidado humanizado. ${ }^{12}$ Este movimento denota a complexidade da dinâmica existente entre exame, processo e cuidado.

\section{METODOLOGIA}

Por visar a expressão de sentidos, a pesquisa é de natureza qualitativa, classificada como descritiva, de acordo com seus objetivos, e exploratória, por sua finalidade de discussão dos aspectos de complexidade no exame físico utilizado para um cuidado pautado pelo processo de enfermagem. ${ }^{13}$

A coleta de dados foi realizada entre o segundo semestre de 2009 e o primeiro de 2010, no Programa de Saúde da Família (PSF) do município de Itaboraí, no Estado do Rio de Janeiro.

Participaram da pesquisa dez enfermeiros de diferentes Unidades Básicas de Saúde, que realizam a consulta de enfermagem, ambiente propício para o desenvolvimento do Processo de Enfermagem. Os depoentes foram identificados com nomes fictícios, inspirados em personalidades da história da enfermagem. Para seleção, os seguintes critérios foram adotados: mínimo de 2 anos de conclusão do curso de graduação; exercício da consulta de enfermagem dentro de suas atividades no PSF; concordância com a participação na pesquisa, e ciência de seus objetivos, através da assinatura do Termo de Consentimento Livre e Esclarecido.

Para coleta de dados, adotou-se a técnica de entrevista semiestruturada, cujas perguntas focalizaram: a preparação para a realização do exame físico, os instrumentos necessários, a subjetividade do cliente, os sentimentos e as preocupações emergentes da interação, a importância da realização do exame no processo de trabalho de enfermagem. Os depoimentos foram gravados em aparelho de tecnologia Mp3 (abreviação de Layer-3 Mpeg, forma de compressão de arquivos sonoros) e transcritos na íntegra pelos pesquisadores em um hipertexto.

Concomitantemente, foram realizadas 65 horas de observação participante, utilizando-se de um roteiro para observação e diário de campo, onde foi registrado o processo de realização do exame físico, cujos dados integram os resultados da pesquisa.

Para análise dos resultados das entrevistas foi adotada a Análise do Discurso do Sujeito Coletivo, proposta por Fenando Lefèvre e Ana Lefèvre. ${ }^{14}$ Esta técnica tem foco primordial no discurso e é oriunda da teoria das representações sociais. ${ }^{13}$ Assim, é munida de figuras metodológicas definidas como expressões chave, ideias centrais - que permitem identificação de posicionamentos e sentidos comuns entre os depoentes realizando a objetivação das ideias - e o seu processo de ancoragem, a qual realiza a assimilação associativa da objetividade dos discursos com ideias e conteúdos anteriores e socialmente aceitos, de modo a produzir conhecimentos acadêmicos, passíveis de generalizações, confrontos e inovações. ${ }^{14}$

A pesquisa foi aprovada pelo Comitê de Ética e Pesquisa da Faculdade de Medicina da Universidade Federal Fluminense com CAAE n. ${ }^{0}$ 2867.0.000.258-09, emitido em agosto de 2009.

\section{RESULTADOS E DISCUSSÃO}

\section{Dialógica e recursividade}

Os achados destacam a complexidade presenciada nas consultas de enfermagem, com foco no exame físico e trazido à tona pelos discursos e observação participante. Entretanto, embora a complexidade não tenha sido completamente explicitada e evidenciada nos produtos da coleta de dados, marcas e indícios de sua presença apontam para um caminho em direção à atitude complexa no cuidado desenvolvido no PSF.

Os discursos demonstram que durante a consulta e a realização do exame físico, fatos inesperados podem acontecer, como expressão do cliente como vergonha, recusa, entre outros comportamentos:

\section{[...] uma vez uma paciente se negou terminantemente a fazer ausculta cardíaca, eu até sugeri nem abrir a blusa, mas ela não deixou. Aí vem várias coisas na nossa cabeça, que ela está escondendo algo, ou até uma doença, ou que tem vergonha, ou que está marcada, mastectomizada e não quer mostrar. (Ana)}

Sobre as diversas reações manifestadas durante 0 exame físico, podem ser destacadas as conceituações de ordem, desordem e incerteza, abordadas por Morin. 0 acaso 
e a desordem brotaram no universo das ciências físicas, "em primeiro lugar, com a irrupção do calor, que é a agitacão-colisãodispersão dos átomos ou moléculas, e depois com a irrupção das indeterminações microfísicas" "5:178, e, enfim, com a explosão originária e dispersão atual do cosmo.

A ordem relaciona-se com constância, estabilidade, regularidade, repetição, determinação e coação. Movidos pela racionalidade científica que valoriza a ordem, por algumas vezes, os profissionais de saúde compreendem que o cliente os pertence, que podem decidir o estado de saúde dele, ao ordenar boas práticas saudáveis aprendidas na universidade, sendo, portanto, dominadores deste saber e exclusivos difusores dele. E movidos por esta forma de pensar, constroem um cliente passivo, com suas vivências e opiniões desconsideradas em seu próprio cuidado ${ }^{15}$ :

[...] a gente faz o exame de acordo com o que aprendeu na faculdade, cefalocaudal, mas não é como se fosse uma receita de bolo, cada paciente é diferente, acontecem várias coisas e eles vêm diferentes uns dos outros, com uma história diferente (Florence)

0 inesperado trazido pela relação entre ordem e desordem evidencia um princípio da complexidade conhecido como dialógico. 0 princípio dialógico surge exatamente para evidenciar ideias contrárias e sua interação. A dialógica entre ordem e desordem é o exemplo mais vivo encontrado no trabalho não somente das equipes do PSF, mas em todos os campos, na saúde, na economia, na política, nas relações ${ }^{5}$ :

[...] os adultos oferecem um pouco de resistência, e aqui, quando eu peço para o paciente deitar, ele já fica meio assim, e tal, meio constrangido com a situação, mas eu procuro fazer realmente o que eu aprendi na universidade, cefalocaudal, palpar e tentar auscultar, mas mesmo assim, você percebe muita resistência. (Virgínia)

0 movimento da ordem e desordem evidencia-se no conflito produzido pela contradição, que tende à desorganização, e se for bem manejada na relação profissional terapêutica leva a uma nova maneira de ordem, esta sendo fruto da dialogicidade e entendimento. Desse modo, é possível perceber como alguns profissionais lidam com a desordem e a incerteza:

[...] no geral as pessoas não conhecem muito bem, por exemplo, quando eu digo 'posso auscultar o senhor?', a pessoa diz 'ah, tá', mas fica sem jeito, não sabe como sentar, se tira a camisa ou não, se fica deitado. Então eu digo 'não precisa, pode ficar à vontade, sentado, eu agora farei uma ausculta, vou ouvir o que diz o seu corpo, e farei assim' aí, eu explico o que vou fazer, exponho somente as partes que eu vou examinar e vejo que eles ficam mais confortáveis. (Virgínia)

A comunicação com o cliente é um recurso que pode ser disposto para enfrentamento da desordem. Neste momento, suas opiniões se juntam com as impressões do profissional em busca de um cuidado, que atinja os objetivos do enfermeiro, como promotor da saúde, e do ser, que é o centro do atendimento.

Surge neste meio outro princípio de complexidade, 0 circuito recursivo. A organização recursiva é a organização cujos efeitos e produtos são necessários à sua própria causa e à sua própria produção. Uma sociedade é produzida pelas interações entre indivíduos, e essas interações produzem um todo organizador que retroage sobre os indivíduos para coproduzi-los pela instrução, linguagem, cultura e outros aspectos. ${ }^{5}$ Portanto, o corpo do cliente produz uma comunicação com o enfermeiro durante 0 exame, e outros aspectos comunicativos emergem durante este cuidado, exaltando aspectos culturais, ambientais e das personalidades dos agentes do cuidado - enfermeiro e cliente:

[...] você sabe, por exemplo, quando um cliente trabalha com obra, as mãos, a pele, é tudo característico. (Imogene)

Morin ${ }^{9}$ afirma que as três instâncias indivíduosociedade-espécie formam uma tríade inseparável. 0 indivíduo humano é, ao mesmo tempo, biológico e cultural, em proporções idênticas; apresenta-se como o ponto de um holograma que contém o todo (espécie, da sociedade) mesmo sendo irredutivelmente singular. De tal maneira, 0 processo de enfermagem desenvolvido a partir das características deste indivíduo, tende a contemplar a multiplicidade do ser.

\section{0 holograma e a reintrodução do conhecimento}

As ações realizadas entre os sujeitos no campo da saúde coletiva, sejam membros da equipe multiprofissional ou clientes, podem desenvolver-se através da compreensão do sujeito complexo, dialógico e relacional, sob o ponto da subjetividade do profissional e do cliente.

Neste sentido, emerge outro princípio da complexidade, o hologramático. 0 holograma é "a imagem física cujas qualidades de relevo, cor e de presença são devidas ao fato de cada um de seus pontos incluírem quase toda a informação do conjunto que ele representa." $5: 259$

Tem-se este tipo de organização nos organismos biológicos: cada célula, até a mais modesta célula da epiderme, contém informação genética do ser global. Nesse sentido, podemos dizer que não só a parte está no todo, mas também que o todo está na parte. 
A mesma coisa, de um modo completamente diferente, acontece na sociedade. Desde o nascimento, a familia nos ensina a linguagem, os primeiros ritos e as primeiras necessidades sociais, imprimindo-nos a cultura. 0 corpo passa a ser um mecanismo complexo, da mesma forma que a sociedade é, e ambos existem noutro, sugerindo que a saúde também deva realizar esta consideração em suas aplicações ${ }^{16}$ :

Temos que saber que é uma pessoa que está ali, então examinamos de acordo com as necessidades dela. E eu acho que tudo influencia sim, onde ela mora, a cultura, o que ela sabe, isso vai vir no corpo dela e quando eu examino, é uma forma de comunicação, o corpo fala." (Virgínia)

0 deslocamento de uma explicação simplificadora na atenção ao indivíduo é tratada na abordarem do diagnóstico de enfermagem, ${ }^{17}$ assim ressaltam-se que os desacordos clínicos podem se reportar ao processo terapêutico e aos resultados esperados, e, para minimizá-los, o profissional deve considerar além do diagnóstico, as condições do cliente, disponibilidade de recursos, custos e experiência da equipe. ${ }^{17}$

0 diagnóstico de enfermagem é uma fase subsequente ao exame físico no processo de enfermagem, pois, através dos achados emergentes ao exame, é concretizada a nomeação dos problemas. Divergências entre a situação real e a inferência feita pelo profissional podem ocorrer por diversos fatores, como o preparo do examinador, o examinado e sua variações biológicas e psicológicas, o exame físico (embasamento teórico e técnico, ambiente, instrumentos utilizados) e o processo diagnóstico.

0 processo de enfermagem requer o emprego do conhecimento apreendido de forma a promover o seu retorno à situação em questão e seu emprego adequado. A este movimento Morin ${ }^{8}$ dá o nome de princípio de reintrodução do conhecimento, útil durante a interpretação dos dados fornecidos pelo exame físico.

A reintrodução do conhecimento em todo conhecimento opera a restauração do sujeito e torna presente a problemática cognitiva central: da percepção à teoria cientifíca, como dito sobre a experimentação; "todo conhecimento é uma reconstrução/tradução por uma mente/cérebro, numa cultura e num tempo determinados." $5: 39$

A complexidade é fruto de um exercício cognitivo. A aprendizagem para contextualizar os conhecimentos depende da capacidade de pensar, e, por sua vez, o pleno emprego de uma inteligência geral garante a contextualização dos conhecimentos. É necessário caminhar e retornar, voltar a caminhar e avançar. ${ }^{5}$

Foi possível observar alguns destes aspectos na consulta de enfermagem: o cliente em questão era um senhor com diagnóstico de diabetes mellitus e tinha uma úlcera de perna. Associando o quadro patológico com o que via, a enfermeira pôs-se a checar os pulsos pediosos, que estavam diminuídos, a temperatura local, sem alterações à palpação, o odor fétido, a aparência da lesão, com bordas altas, irregulares e um pouco de tecido desvitalizado. Ao investigar o estilo de vida do cliente, percebeu um homem que tinha uma alimentação desregrada e empobrecida nutricionalmente, e um regime de trabalho que ocupava todo seu dia, como servente de obras. Os valores de pressão arterial e glicemia encontravam-se aumentados.

Compreendendo estas características e associando ao conhecimento adquirido e experenciado, a enfermeira verificou que o cliente tinha uma baixa perfusão sanguínea periférica, infecção no local da lesão, aumento das complicações crônicas referentes ao diabetes mellitus, mas também associadas aos aspectos de estilo de vida deste cliente. A partir deste momento, as decisões tomadas em conjunto com o cliente iriam articular estes achados anatômicos e fisiológicos à vida do cliente, em busca de seu cuidado. Portanto, os recursos profissionais sistematizados buscam realizar ordem, para cuidar e intervir terapeuticamente, mas ela precisa partir de um processo de avaliação integral, compreendendo a emersão da desordem produzida pelo conflito, pelas alterações biopsíquicas vinculadas à realidade social e cultural da pessoa.

Uma constante associação é requerida pela prática e teoria, de modo a levar a constantes reflexões e adaptaç̃̃es do processo de enfermagem. Não obstante, o enfermeiro, no exercício de sua avaliação do cuidado prestado, é constantemente estimulado a pensar, associando os conteúdos aprendidos à situação em foco, desenvolvendo o raciocínio clínico de enfermagem de modo integral e interdisciplinar.

0 termo raciocínio clínico é utilizado na literatura científica para designar os processos mentais envolvidos no atendimento aos usuários dos sistemas de saúde ${ }^{18}$ :

não adianta palpar o abdome e relatar que ele está rígido ou se tem peristalse, mas saber em que esse dado vai contribuir pro cuidado. (Rosalda)

Em todo o planejamento do cuidado do enfermeiro, 0 raciocínio clínico se faz presente: na descoberta dos dados - e nesta fase destaca-se o exame físico -, no diagnóstico dos fenômenos, na escolha de intervenções apropriadas e na avaliação dos resultados obtidos. A formulação diagnóstica contém as expectativas de intervenções e resultados possíveis, em dado contexto, e depende das pessoas envolvidas (enfermeiro, cliente, família, comunidade) e dos relacionamentos que são estabelecidos entre as pessoas.

A tomada de decisão dentro deste processo, seja a partir de análises indutivas, dedutivas ou intuitivas, permeada pela ética, torna o raciocínio clínico um processo fundamentalmente inter-relacional, contextualizado na prática do cuidado. ${ }^{18}$ Este raciocínio deve estar atrelado à percepção de si, do contexto, dos sentimentos e das habilidades psicomotoras do profissional que cuida. Ao mesmo tempo em 


\section{Exame físico e processo de enfermagem na complexidade}

que a aplicação do cuidado é integral, deve existir um movimento do enfermeiro em cuidar-se e estar assim conectado:

quando a gente percebe que é um ser humano que está ali, pra ser cuidado, a gente pensa na maneira como gostaria de ser cuidado, com respeito e ética profissional, então é preciso tocar com cuidado e fazer com que aquilo que você acha realmente sirva pro bem da pessoa. (Dorothea)

A proficiência na tomada de decisão, assim, passa a ser um ponto crucial. Não basta somente saber como obter os dados através do exame físico, ou que conhecimento regerá a técnica empregada, o enfermeiro tende a desenvolver habilidades e competências cognitivas, afetivas e sociais, fundamentais para o raciocínio clínico. ${ }^{10,11,18}$

Ao nos depararmos com a complexidade de realizar julgamentos, tomar decisões e ser responsáveis pelo resultado de nossas ações, principalmente sabendo que estas decisões e ações irão interferir na vida de outras pessoas, percebemos que estamos diante de um mundo desconhecido e de um desafio de proporções maiores que a nossa capacidade imediata de adaptação.

Assim, como afirmam diferentes estudos, 2,4,15,16,17 o processo de formação acadêmica da enfermagem moderna baseou-se, predominantemente, em conhecimentos provenientes das ciências biológicas, em disciplinas estanques, incorporados de forma fragmentada. Através da reflexão desta realidade, os autores destes ensaios, tal como as reflexões desta pesquisa, almejam mudanças que favoreçam a capacitação de profissionais que exerçam um cuidado rumo à atitude transdisciplinar e complexa.

A partir das características da complexidade evidenciadas na coleta dos dados e da necessidade de raciocínio clínico para desenvolvimento do processo de enfermagem, tendo como um dos pontos de partida o exame físico, desenvolveu-se o Discurso do Sujeito Coletivo, baseado nas concepções de todos os enfermeiros participantes da pesquisa, intitulado "Aspectos de complexidade na realização do exame físico":

ainda não compreendo a complexidade como regente da realização do exame físico em minhas consultas no PSF, mas, até mesmo involuntariamente, alguns de seus aspectos marcam o meu fazer. Como na necessidade de reunir técnica, conhecimento, habilidade, compreensão do outro, comportamento ético, valorização da história de vida e do ambiente, com vistas a integrar um sujeito que é múltiplo em seu próprio cuidado, e a me estimular, como também um sujeito múltiplo a raciocinar criticamente e reflexivamente sobre o meu fazer como enfermeiro. (Enfermeiros PSF, $n=10$, 2010)

\section{CONSIDERAÇÕES FINAIS}

0 exame físico requer conhecimento, prática, técnica e acurácia, para seu desenvolvimento, elementos que conversam dentro de uma esfera complexa. 0 conhecimento embasa 0 exame, que detém a técnica, desenvolvida através do saber e do fazer, que por sua vez trará a tona dados que precisarão ser pensados e repensados para a tomada de uma decisão clínica em conjunto com o cliente, família e comunidade.

A enfermagem tem como responsabilidade realizar suas atividades demarcando sua especificidade, baseada na ciência e destacando o que é concernente à profissão, a exemplo do processo de enfermagem. Para isso, o alicerce em pesquisas e base conceitual própria oferece aos enfermeiros a capacidade de definir os problemas pelos quais são estritamente responsáveis. Entretanto, para a complexidade, não basta apreender o conhecimento, mas se apropriar dele de modo integrado, de modo a identificar os componentes subjetivos, objetivos e relacionais e que emergem na prática do exame físico de enfermagem em seu contexto.

Os dados obtidos durante a realização do exame físico permitem a realização do diagnóstico de enfermagem, o planejamento das ações e implementações do cuidado. A identificação dos problemas do cliente, as decisões tomadas e o pensamento sobre este processo requerem do enfermeiro 0 raciocínio clínico, que por sua vez irá envolver elementos importantes tais como: competência cognitiva, habilidades psicomotoras e experiência, integrados pela percepção intuitiva da situação como um todo, ressaltando a dialógica, a recursividade e o holograma envolvidos neste caminhar.

A enfermagem busca se consolidar como prática científica, de modo que a sistematização da assistência contribui para sua especificidade e ao mesmo tempo permite lidar com a complexidade do cuidado em saúde. 0 estudo do exame físico possibilitou essa contribuição, por meio da visão complexa, articulando as habilidades técnicas, com conhecimento sobre 0 corpo, a conceitos das ciências humanas e sociais. Essa pesquisa registra um contexto atual em que a tecnologia da enfermagem se faz necessária, mas, de modo concomitante, considera como emergente a mudança de paradigma na saúde, saindo de uma perspectiva mecanicista e fracionada para uma visão integral e complexa, devendo ser consideradas pesquisas e inovações.

\section{REFERÊNCIAS}

1. Franco JJS. Orientação dos alunos em ensino clínico de enfermagem: problemáticas específicas e perspectivas de atuaç̧ão. Rev Invest Enferm. 2000 fev; 1: 32-49.

2. Kimura M. Ensino e aprendizagem do exame físico: análise do processo pelo exame das pupilas [tese]. São Paulo: Escola de Enfermagem, Universidade de São Paulo; 1991. 
3. Carvalho V. Por uma epistemologia do cuidado de enfermagem e a formação dos sujeitos do conhecimento na área da enfermagem: do ângulo de uma visão filosófica. Esc Anna Nery. 2009; 13(2); 406-14.

4. Teixeira ER. A Crítica e a sensibilidade no processo de cuidar na enfermagem. Esc Anna Nery. 2004 dez; 8(3): 361-69.

5. Morin E. Ciência com consciência. Edição revista e modificada pelo autor. $12^{\mathrm{a}}$ ed. Rio de Janeiro: Bertrand Brasil; 2008.

6. Alfaro-Lefevre R. Aplicação do processo de enfermagem: promoção do cuidado colaborativo. $5^{\text {a }}$ ed. Porto Alegre: Artmed; 2005.

7. Amante LN, Rossetto AP, Schneider DG. Sistematização da assistência de enfermagem em unidade de terapia intensiva sustentada pela Teoria de Wanda Horta. Rev Esc Enferm USP. 2009 mar; 43(1): 5464.

8. Morin E. Introdução ao pensamento complexo. $3^{\mathrm{a}}$ ed. Porto Alegre: Sulina; 2007.

9. Morin E. 0 método 6: ética. $2^{\text {a }}$ ed. Porto Alegre: Sulina; 2005.

10. Resende E. 0 livro das competências: desenvolvimento das competências: a melhor autoajuda para pessoas, organizações e sociedade. $2^{\mathrm{a}}$ ed. Rio de Janeiro: Qualitymark; 2003.

11. Rios TA. Ética e competência. Coleção questões da nossa época. $16^{\mathrm{a}}$ ed. São Paulo: Cortez; 2006.

12. Ministério da Saúde.(BR). Secretaria de Atenção à Saúde. Política Nacional de Humanização da Atenção e Gestão do SUS. Clínica ampliada e compartilhada. Brasília(DF); 2009.

13. Leopardi MT. Metodologia da pesquisa na saúde. Santa Maria: Palloti; 2006.

14. Lefèvre $F$, Lefèvre $A .0$ discurso do sujeito coletivo: um novo enfoque em pesquisa qualitativa. São Paulo: EDUCS; 2003.

15. Sabóia VM. A mão dupla do poder. Niterói: EdUFF; 1997.

16. Silva AL, Ciampone MHT. Um olhar paradigmático sobre a assistência de enfermagem: um caminhar para o cuidado complexo. Rev Esc Enferm USP. 2003; 37(4): 13-23.

17. Carvalho EC, Kusumota L. Processo de enfermagem: resultados e conseqüências da utilização para a prática de enfermagem. Acta Paul Enferm. 2009; 22( n.esp): 554-57.

18. Cerullo JASB, Cruz DALM. Raciocínio clínico e pensamento crítico. Rev Latino-am Enfermagem. 2010 fev; 18(1): 124-29. 